\title{
Tools for Assessing the Robustness of Electrical System against Voltage Dips in terms of Amplitude, Duration and Frequency
}

\author{
P. Caramia ${ }^{1}$, P. Varilone ${ }^{2}$, P.Verde ${ }^{2}$, L. Vitale ${ }^{2}$ \\ ${ }^{1}$ Dept of Engineering, University of Napoli Parthenope Centro Direzionale di Napoli, Isola C4 - 80143 Naples, Italy \\ Phone/Fax number:+0039, e-mail: pierluigi.caramia@uniparthenope.it \\ ${ }^{2}$ Dept of Electrical and Information Engineering, University of Cassino e del Lazio Meridionale \\ Via G. Di Biasio, 43, 03043 Cassino, Italia \\ Phone/Fax number:+0039776 2993636, e-mail: verde@unicas.it
}

\begin{abstract}
The method of fault position is useful for characterizing power-system performance in the presence of voltage dips due to faults. It is based on short-circuit simulations repeated for all the system nodes and for many points along the system lines: fault voltages that are below a preset threshold are the required voltage dips. These dips are stored in so-called dip matrices, which contain only the dips in all the system nodes when faults occur at points along the lines. Graphical presentation of dip matrices has been proposed as a valuable tool to ascertain the critical area for system performance; this graphical visualization immediately correlates dip severity in terms of amplitude with colours defined by a proper scale. This paper proposes a new graphical representation of the During Fault Voltage matrices that allow accounting for also the dip frequency that is a very important aspect for assessing the voltage dip severity. New robustness indices are also proposed to synthesize bus performance in terms of affected and exposed areas able to account for not only the amplitude of the residual voltage but also the frequency. All the concepts are introduced and illustrated with reference to a real distribution systems.
\end{abstract}

\section{Key words}

Index Terms, Power Quality, Voltage Dip

\section{Introduction}

The Power Quality (PQ) disturbances can be classified in two main categories: Variations and Events. Variations are relatively small deviations of waveform characteristics around their normal or ideal values, and are typically continuous. Events are conspicuous deviations of waveform characteristics around their normal or ideal values, and are typically not continuous. Voltage dips falls into the category of events, and can originate in systems operating both in normal and in faulted conditions. In

P. Varilone, P. Verde, and L. Vitale are with the Department of Electrical and Information Engineering, University of Cassino, Via Di Biasio, 43, Cassino, Italy (verde@unicas.it).

P. Caramia is with the Department of Engineering, University of Naples "Parthenope", Centro Direzionale, Isola C4, Napoli, Italy (pierluigi.caramia@uniparthenope.it) particular, the most frequent voltage dips are due to short circuits, especially those of concern for customers.

The availability of tools for the analysis and prediction of system performance in terms of voltage dips is of great interest. The voltage dip frequency is, in general, so low that estimation to an acceptable degree of accuracy can be deduced only after several years of measurements [1]. Moreover, the started regulation of National Authorities, as in the case of Italy, pushes the utilities toward the adoption of adequate measures to respect the quality objectives also for the voltage dips. To choice and implement optimal solutions, theoretical analysis of electrical power system aimed to estimate their performance in terms of voltage dips has a strategic value. Voltage dips can be simulated using the Fault Position method (FP) [2]. This method can offer a global vision of electrical power system response to faults, both for meshed system and for radial networks. The application of FP has been simplified by the introduction of the so called 'During Fault Voltage' (DFV) matrix, which is a bidimensional vector of voltages. Each element $(i, j)$ represents the vector of the during fault voltage in node $i$ when a short circuit occurs at node $\mathrm{j}$. The DFV matrix illustrates the properties of all dips in all nodes of the system and aggregates information on dip propagation around the network. Applying the FP method and using the DFV matrix it is possible to have information regarding:

- $\quad$ propagation of voltage dips around the network;

- $\quad$ amplitude of voltage dips for all nodes;

- $\quad$ amplitude of voltage dips caused by each node;

- nodes where the faults are critical due to the voltage dips that they cause at other nodes;

- $\quad$ nodes where loads could experience the largest number of voltage dips.

Immediate information on voltage dip performance for the entire system obtained by FP method can be easily and quickly visualized by a graphical colour scheme proposed in $[3,4]$. As an example, Fig. 1, shows the graphic visualization of the DFV matrix for the real Italian distribution network, depicted in Fig.2, where three-phase faults were simulated. 


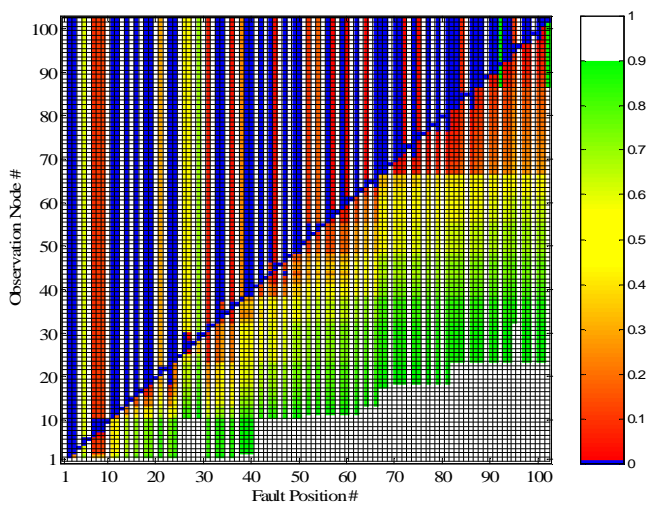

Fig. 1 Graphic visualization of DFV matrix for any three-phase faults

With reference to Fig. 1, the DFV cells are represented by colours corresponding to their amplitude by means of the grade scale reported in the same figure (blue colour for interruptions, shades of red for severe deep dips, shades of yellow for medium deep dips, shades of green for light deep dips and white colour for no dips).

In this paper, new indices are proposed for describing bus performance not only in terms of the amplitude of the residual voltage but also of frequency. The proposal of these new indices starts from the concept of the robustness of a system referred to the voltage dips.

Compared to the papers [4] and [5] by the same authors, this paper first presents new matrices DFV related to the probability of failure, and then the corresponding new indices which include information on the frequency of the voltage dips.

All the concepts are introduced and illustrated with reference to a real distribution systems.

\section{The concept of Robustness: recall and indices}

Power system robustness referred to the voltage dip is defined as the intrinsic capacity of an electrical power system to maintain assigned disturbance levels when the external conditions change [6,7]. The graphic visualization of the DFV matrix allows to immediately ascertain if (and where) the changes of external conditions affect the electrical power system's ability to maintain dip severity at assigned levels.

To synthesize node performances in terms of affected and exposed areas, robustness indices were introduced in [4],[5],[6],[8]. The definitions of these indices, called Affected Area Dimension index, Exposed Area Dimension index and Robustness Index, are:

- $\quad$ Affected Area Dimension index of $\mathrm{k}^{\text {th }}$ node $\left(A A D_{\kappa}\right)$ is the number of the network's nodes experiencing a voltage dip in presence of a fault in $\mathrm{k}^{\text {th }}$ node.

- Exposed Area Dimension index of $\mathrm{k}^{\text {th }}$ node $\left(E A D_{\kappa}\right)$ is the number of the network's nodes that, if interested by faults, produce a voltage dip in the $\mathrm{k}^{\text {th }}$ node.

- Robustness Index of $\mathrm{k}^{\text {th }}$ node $\left(R I_{\kappa}\right)$ is defined as:

$$
R I_{k}=A A D_{k} / E A D_{k}
$$

Referring to the colour visualization of the DFV matrix (Fig. 1), $A A D_{k}\left(E A D_{\kappa}\right)$ index corresponds to the number of no white and no blue cells in the $k^{\text {th }}$ column (row) of the graphic visualization of the DFV matrix.

As an example, the Figs. from 3 to 5 show the values of the index $A A D_{\kappa}, E A D_{\kappa}$ and $R I_{\kappa}$ calculated by means of the DFV matrix whose graphical visualization is illustrated in Fig.1. The plot of $A A D_{\kappa}$ in Fig. 3 presents three main zones with different characteristics:

Zone inside the dashed contour; it is characterised by a reduced range of variation (the values of $A A D_{\kappa}$ vary between 80 and 100 nodes); this zone mainly refers to nodes on short lines feeding the MV/LV stations. In particular these nodes are the ones characterized in Fig. 1 by the columns with the greatest number of cells with colour from green to red.

Zone inside the continuous contour; it $\mathrm{s}$ is characterised by a larger range of variation (the values of $A A D_{\kappa}$ vary between 10 and 80 nodes), moreover the values of $A A D_{\kappa}$ increase along $\mathrm{x}$-axis. This last characteristic is particularly unexpected since along the $\mathrm{x}$-axis the electrical distance from the primary station mostly increases. Indeed, it has to be noted that the nodes closer to the primary station cause mainly interruptions, instead the nodes farther away from the primary stations mainly cause voltage dips.

A lower zone characterised by zero value of $A A D_{\kappa}$; this

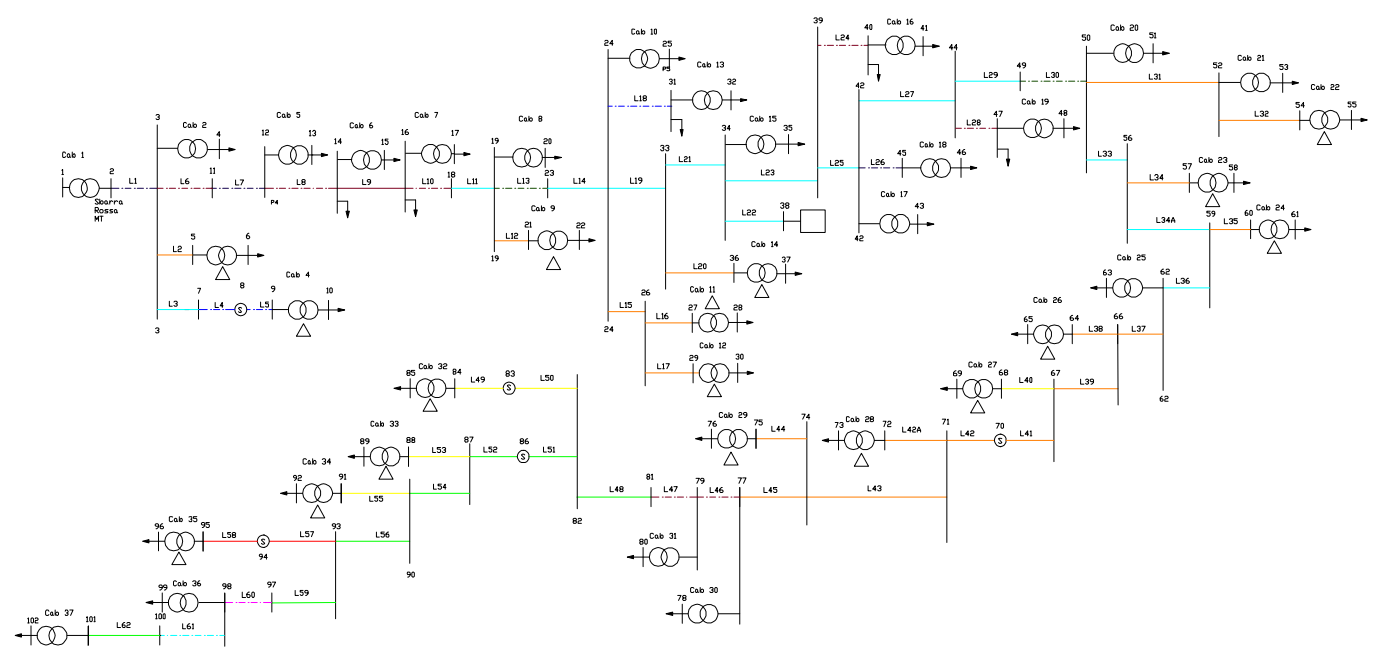

Fig.2 Real electrical distribution system analysed 


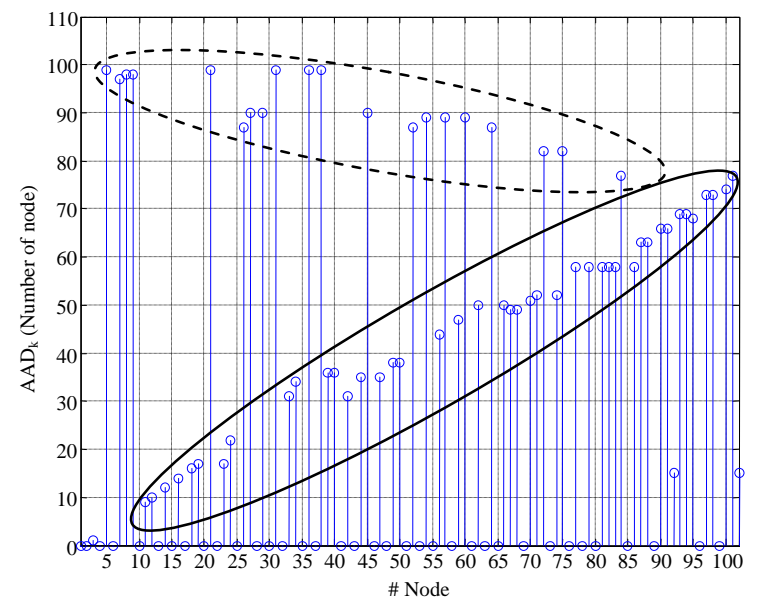

Fig. 3 Plot of Affected Area Dimension index of the Distribution System

zone refers to the LV nodes; in fact, the faults in these nodes produce reduced values of short circuit currents for the limiting action of the impedances of the MV/LV transformer (these nodes are the ones characterized in Fig. 1 by columns having a greater number of white cells).

The plot of $E A D_{\kappa}$ (Fig. 4) is characterized by a regular trend; the highest values arise for the central nodes (nodes between 24 and 66) that experience the voltage dips for failures occurring both upstream and downstream.

The trend of $R I_{\kappa}$ (Fig. 5) practically reproduces the same behaviour of the $A A D_{\kappa}$ but with a reduced range of variation due to the high value assumed by $E A D_{\kappa}$ for the central nodes of the network. The values assumed by $R I_{\kappa}$ are less than one, greater than one and equal to zero. In particular, a $R I_{\kappa}$ greater than one indicates that the node $\mathrm{k}$ causes more dips than it experiences (this occurs for strong nodes), a $R I_{\kappa}$ value less than one indicates that the node $\mathrm{k}$ experiences more dips than it causes (this occurs for powerless nodes), $R I_{\kappa}$ value equal to zero indicate that the node $\mathrm{k}$ experience dips without causing them (this occurs for LV busbars). With reference to the considered test electrical distribution system the correlation between short circuit power magnitude and $A A D_{\kappa}, E A D_{\kappa}$ and $R I_{\kappa}$ indices has been analysed. In particular, the figures 6,7 and 8 show the $A A D_{\kappa}, E A D_{\kappa}$ and $R I_{\kappa}$ indices versus the value of the short circuit power.

Fig. 6 evidences that nodes with low values of short circuit power are characterized by the highest values of the $A A D_{\kappa}$ index. High values of short circuit power, in fact, are typical of nodes very close to the primary station; these nodes, if affected by faults, produce mainly interruptions that are not taken into account by $A A D_{\kappa}$.

Fig. 7 evidences that the nodes characterized by low short circuit power, as foreseeable, are those most exposed to the voltage dips.

Fig. 8 evidences that the nodes characterized by high short circuit power experience more dips than they cause since, when a fault happens at these nodes, they generate mainly interruptions.

Generally, not only amplitude but also duration and frequency characterize the severity of voltage dips.

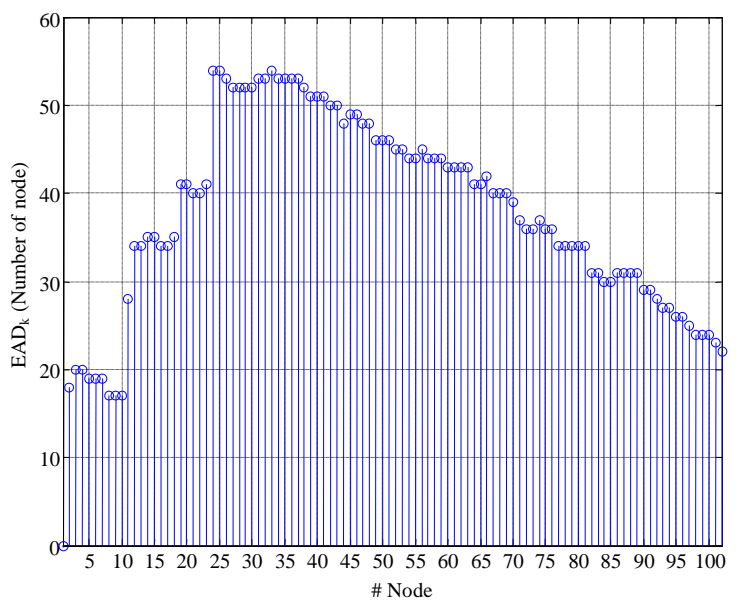

Fig. 4 Plot of Exposed Area Dimension index of the Distribution System

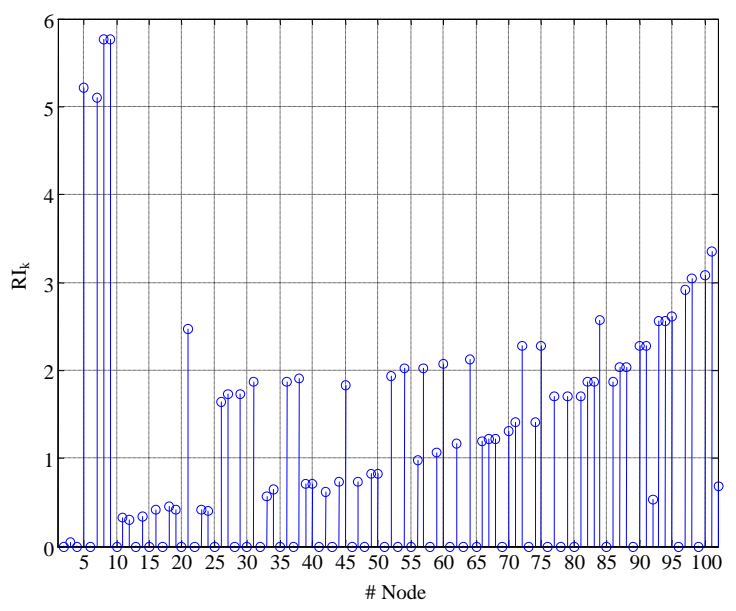

Fig. 5 Plot of Robustness Index of the Distribution System

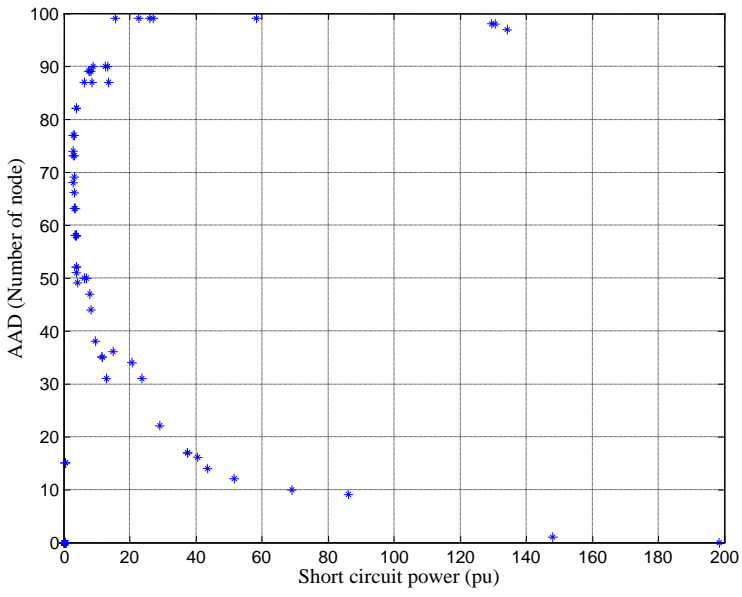

Fig. 6. Plot of Affected Area Dimension index against Short circuit power (p.u.)

To confirm this statement, as an example, the revised standard EN50160 introduces tables reporting dip frequency in function of residual voltage and duration to quantify the network voltage dip performance.

The DFV matrix described up to now gives only information about dip amplitudes, and does not provide any information about duration and frequency. 


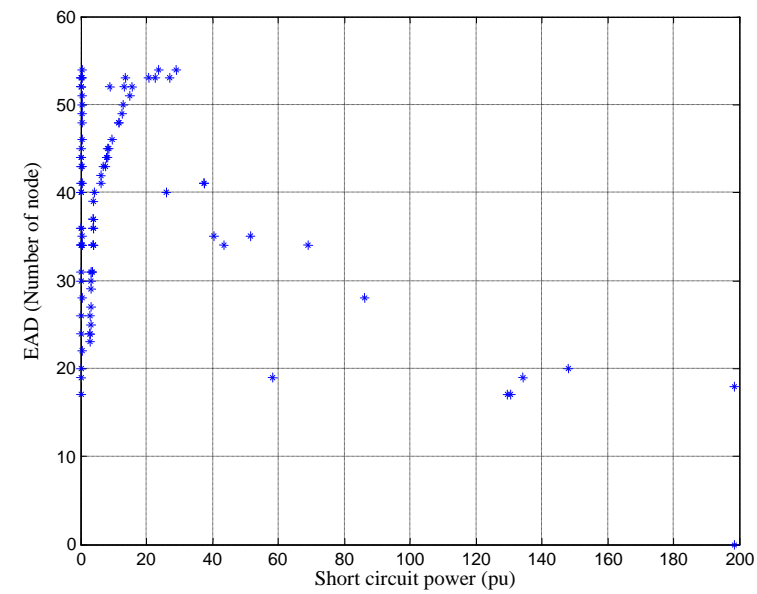

Fig. 7 Plot of Exposed Area Dimension index against Short circuit power (p.u.)

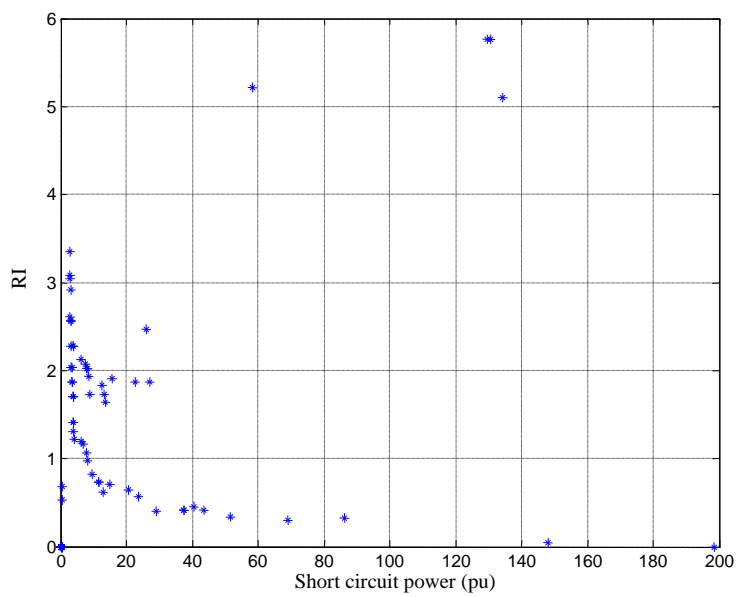

Fig. 8 Plot of Robustness Index against Short circuit power (p.u.)

In the following, duration and frequency of voltage dips are dealt with, and tools to describe these characteristics are proposed ${ }^{2}$.

\section{Voltage dip duration}

The study of the duration of voltage dips requires knowledge of the characteristics of protection devices installed in the network, and of the adopted protection strategy. Moreover, two main cases can be considered: voltage dips due to faults within the distribution network; voltage dips due to faults within the upstream transmission system that feeds the distribution system. In this analysis, only the first case is considered.

Most of the electrical distribution systems has a radial structure and the protection of the network is assigned to the devices installed in to the HV/MV substation. The principal form of protection in distribution system is overcurrent protection. These protections are characterized by different tripping time in function of the value assumed by the overcurrents. Consequently, the voltage dip duration coincides with the fault-clearing time of the protection that, in turn, depends on the current flowing through the protective device.

${ }^{2}$ In this paper the analysis of the voltage dips severity has been effected considering amplitude, duration and frequency and neglecting other factors as, for example, the phase angle jump.
As an example in Fig. 9, once again referred to the considered Italian distribution network, the voltage dip durations, due to three-phase faults in all the busbars, are reported. As foreseeable, dip durations are concentrated on the three fault-clearing times of the installed protective device $^{3}$.

\section{Voltage dip frequency}

The frequency of the voltage dips due to faults is strictly linked to the fault characteristics of the electrical power system in study.

The voltage dip frequency at all network busbars can be obtained from the faults frequency and the calculation of the during fault voltages.

Regarding the fault frequency, network operators often keep fault statistics or are able to provide a reasonable estimate for the fault frequency of the different components present in their system.

Regarding the during fault voltages, as previously described, they can be obtained applying the FP method.

Therefore, to characterize the severity of voltage dips in terms of frequency, the fault voltages contained in the DFV matrix have to be combined with the failure rate of the system components.

To simplify the procedure and without loss of generality, the faults on lines are not directly simulated but their occurrence is accounted for by considering a modified node failure rate [4].

Once again a graphic visualization can be used to quickly obtain the information about the severity of voltage dip in term of frequency. New DFV matrices linked to the node failure rates (in the following indicated with $\mathrm{DFV}_{\lambda}$ symbol) can be obtained using the same graphic tool used to visualize the dip voltage amplitude.

In particular, dividing the fault rates of the network nodes into different ranges, different $\mathrm{DFV}_{\lambda}$ matrices are built, each one corresponding to a specified fault rate.

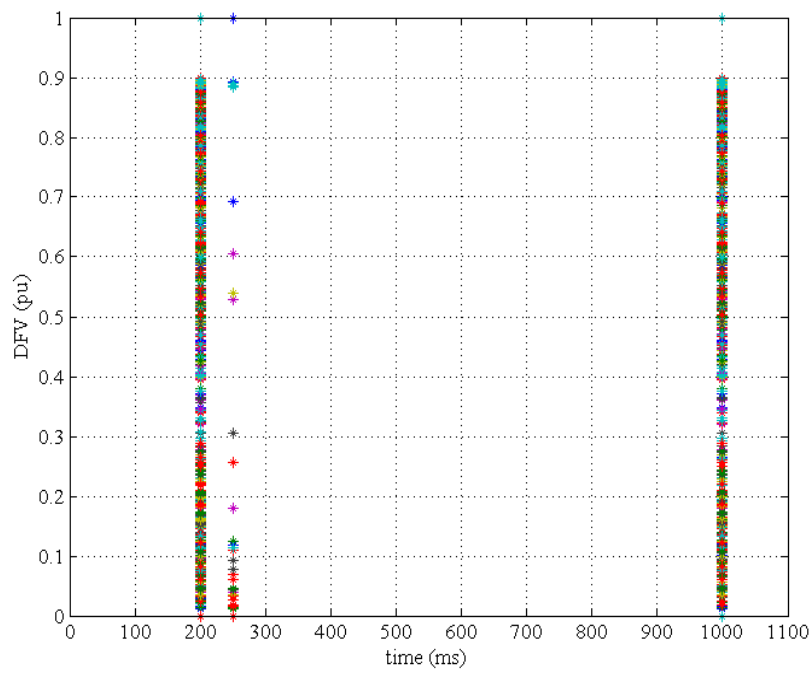

Fig. 9 Amplitude and duration of voltage dips in the considered network

${ }^{3}$ In this study the automatic reclosing of the network used for troubleshooting is not taken into account. 
These matrices are obtained from the classical DFV matrix, extracting the columns of those busbars characterized by the failure rate in the specified $\lambda$ range.

With reference to the Italian distribution network of Fig. 2, two different range of node failure rates have been chosen:

1) $\quad \lambda 1$ range $(0.003 \leq \lambda<0.05)$ faults/years;

2) $\quad \lambda 2$ range $(0.05 \leq \lambda<0.7)$ faults/years.

With the preceding choices, the failure rates of the nodes of cable lines typically fall into the first interval; while the failure rates of the nodes of overhead lines fall into the second interval.

Figs. 10 and 11 show the obtained $\mathrm{DFV}_{\lambda !}$ and $\mathrm{DFV}_{\lambda 2}$ matrices.

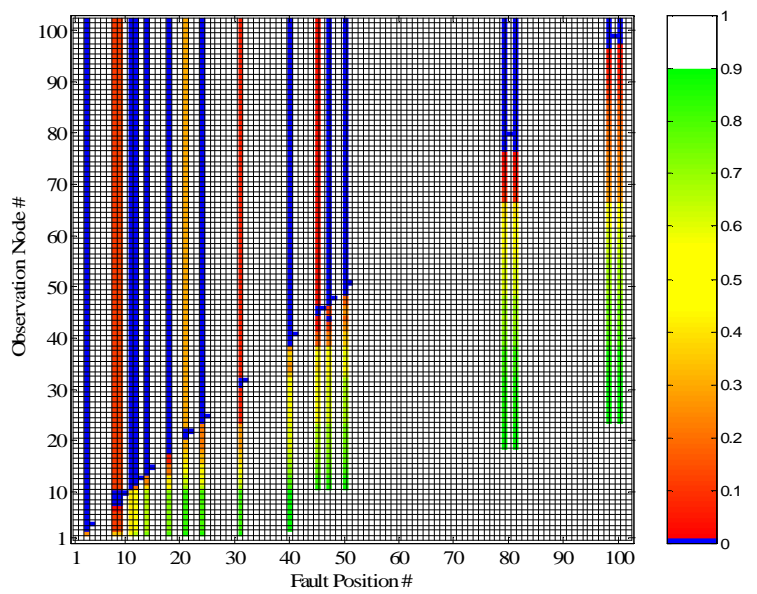

Fig. 10 Graphic visualization of $\mathrm{DFV}_{\lambda 1}$ matrix with $0.003 \leq \lambda 1<0.05$ faults/year

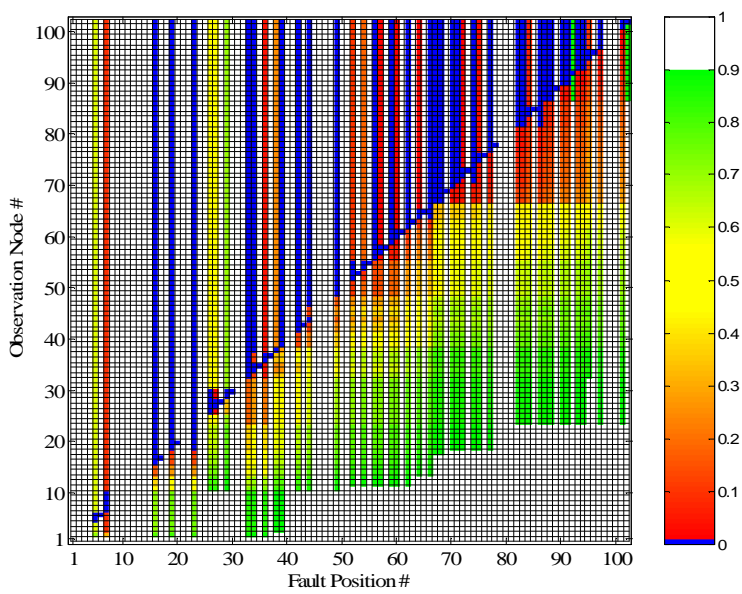

Fig. 11 Graphic visualization of $\mathrm{DFV}_{\lambda 2}$ matrix with $0.05 \leq \lambda 2<0.7$ faults/year

The $\operatorname{DFV}_{\lambda}$ matrices permit to classify the performance of the nodes in function of the voltage dip frequency even if the nodes experience the same voltage dip amplitude, that is the same colour of the cell in the DFV matrix of Fig. 1

From the new $\mathrm{DFV}_{\lambda}$ matrices the following new indices can be defined:

- Affected area dimension index within $\lambda_{i}$ range $\left(A A D^{*}{ }_{\kappa}\right) \lambda_{\mathrm{i}}$ of $\mathrm{k}^{\text {th }}$ node: the number of the nodes experiencing voltage dips in presence of a fault at $\mathrm{k}^{\text {th }}$ node characterized by a failure rate in the $\lambda_{i}$ range.

- Exposed area dimension index within $\lambda_{i}$ range $\left(E A D^{*}{ }_{\kappa}\right) \lambda_{\mathrm{l}}$ of $\mathrm{k}^{\text {th }}$ node: the number of the nodes whose failure rate $\lambda$ is in the $\lambda_{i}$ range that, when experience a fault, produce voltage dips in the $\mathrm{k}^{\text {th }}$ node.

- Robustness index $\left(R I^{*}{ }_{\kappa}\right)_{\lambda_{1}}$ within $\lambda_{i}$ range: the ratio between $\left(A A D^{*}{ }_{K}\right) \lambda_{\mathrm{l}}$ and $\left(E A D^{*}{ }_{K}\right) \lambda_{\mathrm{i}}$.

Figs. 12 to 17 show the indices $\left(A A D^{*}{ }_{\kappa}\right)_{\lambda 1},\left(E A D_{\kappa}{ }^{*}\right)_{\lambda 1}$, $\left(R I^{*}{ }_{\kappa}\right)_{\lambda 1}, \quad\left(A A D^{*}{ }_{\kappa}\right)_{\lambda 2}, \quad\left(E A D_{\kappa}{ }^{*}\right)_{\lambda 2}, \quad\left(R I^{*}{ }_{\kappa}\right)_{\lambda 2}$ for the considered distribution system.

The aforementioned new indices allow comparing the nodes characterized by the same affected or exposed area in function of the dip frequency. For example, referring to the Figs. 12 and 13, the busbars \#27, \#28 ad \#45 have about the same value of $\left(A A D^{*}{ }_{\kappa}\right) \lambda$, that is around 90 . However, the performance of \#27, \#28 is worse than \#45. In fact, the nodes $\# 27, \# 28$ are characterized by a higher value of dip frequency since their indices $\left(A A D^{*}{ }_{\kappa}\right) \lambda$ belong to the higher range $\lambda 2$ of node failure rates. Similar considerations can be effected in terms of exposed area comparing the Figs. 14 and 15, and in terms of robustness comparing the Figs. 16 and 17.

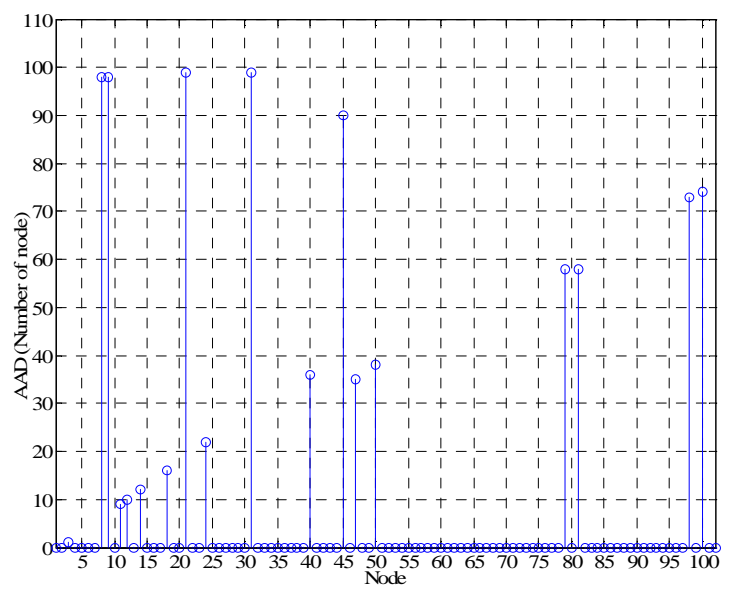

Fig. 12 Plot of $\left(\mathrm{AAD}_{\mathrm{k}}\right)_{\lambda 1}$ with $0.003 \leq \lambda 1<0.05$ faults/year

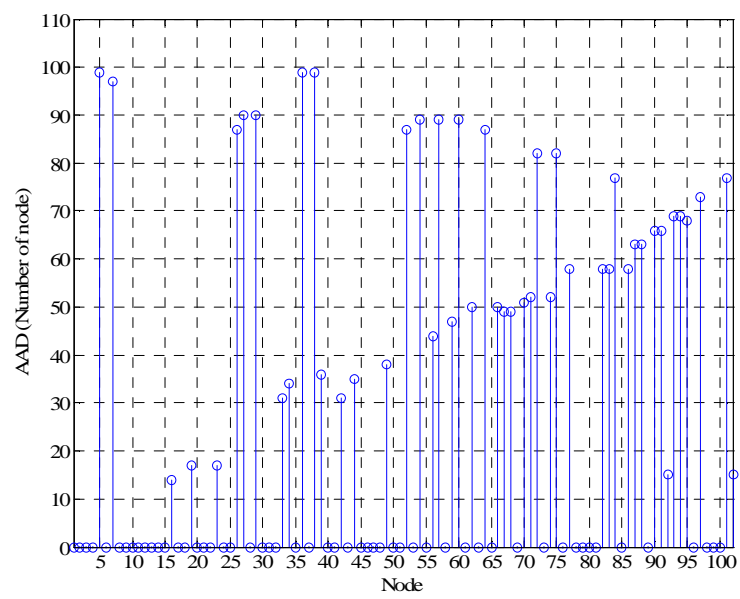

Fig. 13 Plot of $\left(\mathrm{AAD}^{*}\right)_{\lambda 2}$ with $0.05 \leq \lambda 2<0.7$ faults/year 


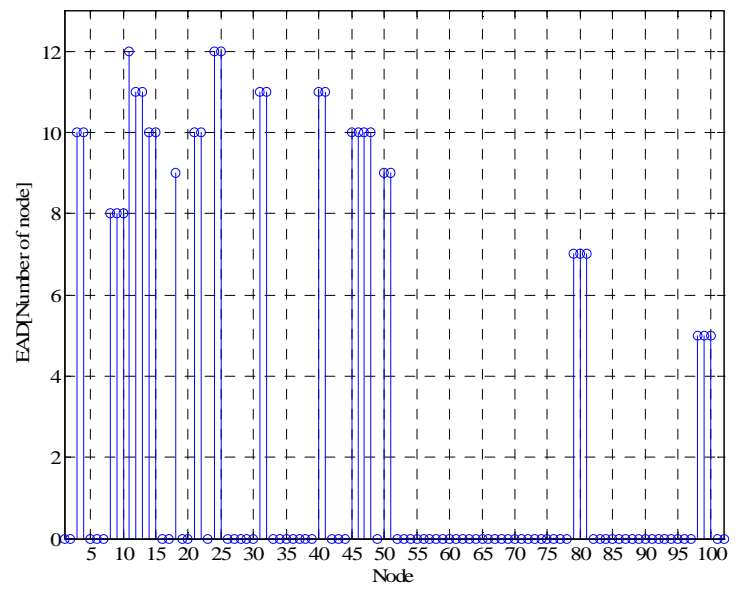

Fig. 14 Plot of $\left(\mathrm{EAD}^{*}{ }_{\mathrm{k}}\right)_{\lambda 1}$ with $0.003 \leq \lambda 1<0.05$ faults/year

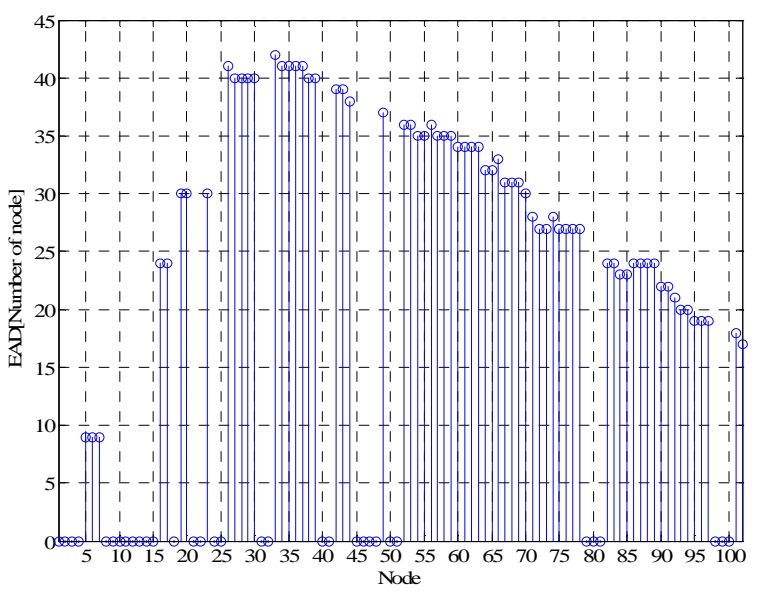

Fig. 15 Plot of $\left(\mathrm{EAD}_{\mathrm{k}}\right)_{\lambda 2}$ with $0.05 \leq \lambda 2<0.7$ faults/year

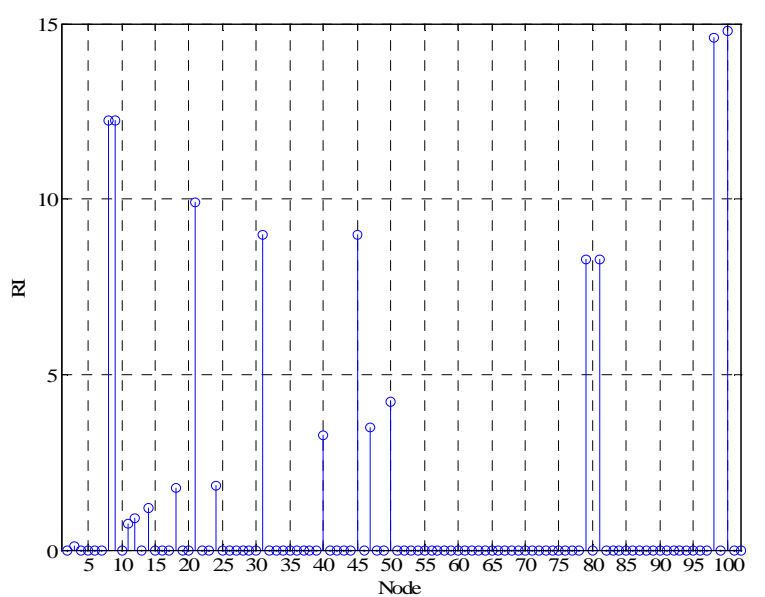

Fig. 16 Plot of $\left(\mathrm{RI}^{*}{ }_{\mathrm{k}}\right)_{\lambda 1}$ with $0.003 \leq \lambda 1<0.05$ faults/year

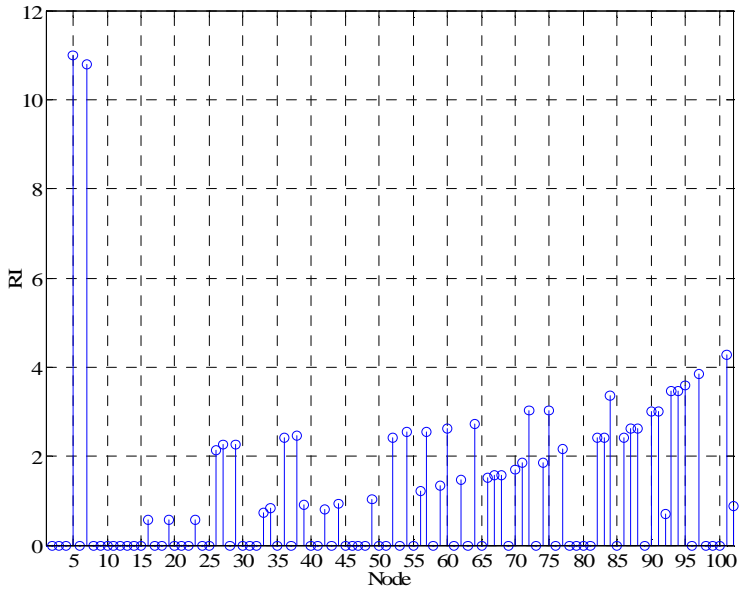

Fig. 17 Plot of $\left(\mathrm{RI}^{*}{ }_{\mathrm{k}}\right)_{\lambda 2}$ with $0.05 \leq \lambda 2<0.7$ faults/year

\section{Conclusions}

This paper contributes to define new tools to quantify the voltage dip performance of an electrical distribution system. In particular new DFV matrices able to take into account the failure rate of the system component are introduced. These matrices permit to have information about severity of voltage dips not only in terms of amplitude but also in terms of frequency.

Using the proposed DFV matrices, new indices have been also introduced to account for the voltage dip frequency.

The new DFV matrices together with indices represent useful tools to define structural modifications in an electrical system to improve its voltage dip performance.

\section{Reference}

[1] M.H.J. Bollen, "Understanding power quality problems: voltage sags and interruptions", New York, IEEE Press, 1999.

[2] IEEE Std 493-1997: "Recommended Practice for the Design of Reliable Industrial and Commercial Power Systems".

[3] P. Verde, R. Chiumeo, I. Mastandrea, F. Tarsia, Definizione di procedure e metodologie per il monitoraggio della "robustezza" e dell'adeguatezza del sistema di potenza, CESI-Ricerca di sistema, Report A5-053071, www.ricercadisistema.it/documenti (in Italian), December 2005.

[4] G. Carpinelli, P. Caramia, C. Di Perna, P. Varilone, P. Verde, "Complete Matrix Formulation of fault-position method for voltage-dip characterization", IET Generation, Transmission \& Distribution, Volume 1, Issue 1, January 2007, pp. 56 - 64.

[5] C. Di Perna, G. Olguin, P. Verde, and M. H. J. Bollen, "On probabilistic system indices for voltage dips," presented at the PMAPS, Ames, Iowa, Sep. 12-17, 2004.

[6] P. Caramia, G. Carpinelli, R. Chiumeo, C. Di Perna, I. Mastandrea, F. Tarsia, P. Varilone , P. Verde, "On Robustness of Distribution Systems against Voltage Dips due to Faults", Proceedings of Speedam 2006, Taormina (IT), May 2006, pp. $1310-1315$.

[7] P. Caramia, G. Carpinelli, C. Di Perna, P. Varilone, "Methods for Assessing the Robustness of Electrical Power Systems against Voltage Dips", IEEE Transactions on Power Delivery, Vol. 24, Issue 1, January 2009.

[8] P. Caramia, G. Carpinelli, C. Di Perna, P. Varilone, and P. Verde, "Fast probabilistic assessment of voltage dips in power systems," presented at the PMAPS, Stockholm, Sweden, Jun. 2006. 